\title{
Análise do perfil sociodemográfico e profissional do Promotor de eventos de Curitiba e Região Metropolitana (Paraná, Brasil)
}

\section{Analysis of the sociodemographic and professional profile of the Event Promoter of Curitiba and Metropolitan Region} (Parana, Brazil)

\section{Mayna de Aquino}

Docente do Curso de Gestão de Turismo em EAD do Centro Universitário Campos de Andrade - Uniandrade, Curitiba/PR, Brasil

E-mail: mayna.aquino@gmail.com

\section{Margarete Araujo Teles}

Docente do Curso de Turismo e do Programa de Pós-Graduação em Turismo da Universidade Federal do Paraná - UFPR, Curitiba/PR, Brasil

E-mail: margateles25@gmail.com 


\section{RESUMO}

Os promotores de eventos conhecidos como receptivos de eventos ou recepcionistas são profissionais com conhecimentos técnicos aplicados a Fase Evento - Operacionalização, que sustentam de forma versátil as funções de recepção, coordenação, produção, entre outras, garantindo a execução das atividades de um evento. Porém, os estudos sobre estes profissionais de eventos são poucos explorados na literatura acadêmica. Assim, por meio da pesquisa bibliográfica, documental e empírica de forma qualitativa e quantitativa com aplicação de formulário online, identificou-se o perfil sociodemográfico, habilidades e a forma de contratação dos promotores de eventos de Curitiba e Região Metropolitana (RM). Os principais resultados apontam que os profissionais que atuam na área de gestão e operacionalização têm formação em marketing e/ou publicidade e recebem rendimentos médios de 1 a 3 salários mínimos. A opção em trabalhar com eventos lhes permite ter dias livres para organizar a vida pessoal. Os contratos são temporários e os pagamentos são por diárias. Nota-se, ainda, que a terceirização e a migração da contratação para o meio virtual fazem parte da área a partir do advento das diversas redes sociais e aplicativos de contato utilizados pelas empresas organizadoras contratantes. Observa-se também, que dada à importância que têm os eventos no desenvolvimento da atividade turística de Curitiba e Região Metropolitana, outros estudos técnicos e acadêmicos devem ser aplicados às empresas organizadoras e promotoras sobre o planejamento e suas fases de organização, considerando que as pesquisas acadêmicas devem auxiliar na inovação e conhecimento do setor de forma sistematizada e aplicada.

Palavras-chave: Eventos. Planejamento. Operacionalização. Promotores de Eventos.

\section{ABSTRACT}

Event promoters known as event receptors or receptionists are professionals with technical knowledge applied to the Event Phase - Operationalization, who versatilely support the functions of reception, coordination, production, among others, ensuring the execution of the activities of an event. However, studies on these event professionals are little explored in the academic literature. Thus, through bibliographical, documentary and empirical research in a qualitative and quantitative form with application of online form, we identified the sociodemographic profile, skills and form of hiring of event promoters from Curitiba and Metropolitan Region (RM). The main results indicate that professionals working in the management and operationalization area have training in marketing and/or advertising and receive average income of 1 to 3 minimum wages. The option to work with events allows them to have free days to organize their personal lives. Contracts are temporary and payments are per day. It is also noted that outsourcing and migration of hiring to the virtual environment are part of the area since the advent of the various social networks and contact applications used by the contracting organizing companies. It is also observed that, given the importance of the events in the development of the tourist activity of Curitiba and the Metropolitan Region, other technical and academic studies should be applied to the organizing and promoting companies about the planning and its stages of organization, considering that the research Academics should assist in innovation and knowledge of the sector in a systematic and applied way.

Keywords: Events. Planning. Operationalization. Event Promoters. 


\section{INTRODUÇÃO}

Os eventos representam um instrumento de divulgação e promoção das organizações reforçando a possibilidade de aproximação entre as empresas e instituições e seu público-alvo, estreitando a relação e fortalecendo a imagem institucional (Arruda \& Tarsitano, 2012). Desta forma, pode-se afirmar que os gestores de eventos, organizadores e planejadores, são também gestores de ideias e projetos para obtenção de resultados de terceiros, visto que a área apresenta uma forte característica profissional: a terceirização (Confederação Nacional Da Indústria [CNI], 2005).

Por envolver diversas necessidades, entre organizações e pessoas, os eventos tornaram-se uma atividade econômica e social de destaque devendo ser tratada de forma profissional abarcando a terceirização, contribuindo para o desenvolvimento do setor em âmbito mundial. Além disto, os eventos estão intrinsecamente atrelados ao mercado do turismo, considerado promissor e capaz de proporcionar crescimento econômico e social com base em investimentos. Por ser um setor competitivo exige profissionalização e engajamento de empresas organizadoras e entidades promotoras envolvidas para se atingir resultados positivos (Andrade, 2007; Matias, 2013; Zanella, 2006).

Dentre muitas contribuições dos eventos, enquanto, uma atividade relacionada ao turismo, pode-se listar o auxílio na manutenção da estabilidade deste mercado no que se refere à sazonalidade turística, pois, têm a possibilidade de manter os períodos de baixa temporada de uma localidade garantindo demanda turística, por meio de captação de eventos e favorecendo a geração de emprego e renda (Oliveira, Gândara, \& Oliveira, 2017).

Para tal, os eventos passam por um processo organizativo chamado de planejamento que vai da definição dos participantes, captação do evento, do local e dos recursos para sua realização, a contratando serviços (parceiros, fornecedores e terceirizados) cujas atividades complementares e de suporte irão atender as demandas específicas do evento (Dotto, Cerezer, Pons, \& Denardin, 2017).

O processo de captação de um evento envolve o poder público, a iniciativa privada e entidades mantidas pela iniciativa privada como os Conventions and Visitors Bureau de cada localidade (Andrade, 2007; Matias, 2013). Neste sentido, os Conventions and Visitors Bureau são agências de fomento, organizações do terceiro setor mantidas por seus associados do trade turístico com o objetivo de alavancar a localidade fazendo a captação de eventos nacionais e internacionais para uma determinada localidade (Nichols, 1989). 
No Brasil, mesmo meio a crise econômica contemporânea, tem-se a necessidade de continuidade e realização de eventos como ferramentas importantes de promoção e venda ou como atividades internas de planejamento e construção de novas estratégias (Martins \& Murad, 2015 como citado em Klein, 2017).

Paixão (2014) afirma que em Curitiba, os eventos movimentam o turismo de negócios e eventos ultrapassando R 1 bilhão por ano, sendo quase 4 milhões de turistas vindos anualmente a cidade, destes, 55\% tem com motivação as necessidades profissionais e, em seguida, a busca por lazer no tempo livre. A capital do Paraná captou de outubro a dezembro de 2013 aproximadamente 20 eventos de grande porte, gerando hospedagens, confirmando a capacidade de atendimento da rede hoteleira local e dos espaços de eventos e sustentando o setor turístico.

De acordo com os dados do relatório anual da International Congress and Convention Association, publicado em junho de 2018, sob o título: Statistics Report Country \& City Ranking; no contexto internacional, Curitiba ocupa o $38^{\circ}$ lugar no ranking dos municípios que mais recebem eventos na América Latina. Em nível nacional, ocupa o $6^{\circ}$ lugar no ranking dos municípios brasileiros mais procurados para realização de eventos perdendo apenas para grandes capitais como: São Paulo, Rio de Janeiro, Florianópolis e Foz do Iguaçu, Brasília e Salvador, tendo realizado cerca de 6 eventos de grande porte no ano de 2017 (International Congress and Convention Association [ICCA], 2018).

Ao considerar toda a movimentação econômica, no que consiste a contratação de serviços complementares e de suporte e, o engajamento das empresas organizadoras como elemento de êxito para execução do planejamento de eventos, foi que se estruturou o objetivo deste estudo: conhecer o perfil sociodemográfico e profissional dos promotores de eventos que são os recursos humanos contratados para trabalhar na execução da Fase Evento Operacionalização para compreender e identificar a terceirização profissional do setor de eventos.

Por meio de observação direta, as autoras levantaram como primeira hipótese que estes profissionais têm formações similares às áreas de turismo, hotelaria e eventos, mas, suas experiências profissionais são oriundas de outras áreas. A segunda hipótese levantada, é de que devido às transformações econômicas e sociais que afetaram as relações de consumo por meio de plataformas digitais, reduziram os intermediários no processo de produção de distribuição de bens e serviços e fez emergir modificações no mercado de trabalho no setor turístico, conhecida como sharing economy (Aquino \& Brambatti, 2018; Aquino \& Silveira, 
2018). As contratações destes profissionais no segmento de eventos passaram a ser majoritariamente online por meio de sites de cadastros das empresas organizadores e/ou por meio de aplicativos de redes sociais em que os contatos profissionais estão ativos, beneficiando incursão de profissionais de outras áreas.

As publicações neste tema são incipientes, pois, compreendem muito mais uma análise de aplicação técnica do que científica. Os promotores de eventos não apresentam relação direta com as empresas promotoras de eventos como será visto nas seções a seguir.

Desta forma, buscou-se compreender um universo profissional por meio de pesquisa online com um formulário composto por perguntas fechadas e abertas para identificar o perfil do promotor de eventos na cidade de Curitiba e Região Metropolitana - RM (Paraná, Brasil), confirmando ou refutando as hipóteses levantadas. Os resultados atingidos são analisados, interpretados e discutidos na seção 5 deste paper.

\section{O PLANEJAMENTO DE EVENTOS E SUAS FASES ORGANIZACIONAIS}

Para explicar o que é planejamento de eventos e suas fases de organização é necessário compreender sobre a temática eventos e sua relação com os recursos humanos.

Um evento é um acontecimento cuja principal característica é o encontro entre as pessoas com uma finalidade específica, o qual constitui um tema principal e uma justificativa para sua realização. As finalidades pelas as quais os eventos acontecem podem ser plurais e apresentam características singulares, o que permite classificá-los por tipos conforme suas áreas de interesse e por suas categorias. Desta forma se têm as tipologias de eventos e suas categorias são aplicadas às características do processo organizativo (Giacaglia, 2003).

Bahl (2004) corrobora com a autora complementando que as atividades programadas para serem desenvolvidas num local e tempo determinados agrupam indivíduos com interesses e objetivos similares, mobilizam a cadeia produtiva e serviços públicos de uma localidade, sendo aquelas, as motivadoras de realização.

Os eventos utilizam como ferramenta organizacional o planejamento que é um processo composto por 3 fases: Pré-Evento, Evento (ou Per e Trans) e Pós-Eventos. As atividades relacionadas no planejamento de um evento podem ser inúmeras e vão depender da finalidade e tipo de cada evento, para agregar as características necessárias de estruturação (Cesca, 1997; Matias, 2013).

Porém, os eventos como um todo, apresentam uma Fase de Concepção em que são elaboradas estratégias de ação para captação (do evento, do local e dos recursos para sua realização) e as Fases de Captação do evento para um local determinado (Preparação para 
captação, Captação e Pós-captação) que, irão auxiliar nas fases do planejamento viabilizando a contratação de serviços (Andrade, 2007; Cesca, 1997; Giacaglia, 2003; Matias, 2013; Zanella, 2006).

Ao conceber o evento, quando se reconhece às necessidades do mesmo, elaboram-se alternativas para suprir as demandas de execução. Ao identificar objetivos, coletam-se informações necessárias listando os recursos para estimar os custos, recursos e tempo, assim estabelecem-se diretrizes para elaboração do projeto. É o momento em que o planejamento está ganhando forma e este processo é um esforço organizacional que garantirá que todas as fases do evento sejam realizadas (Matias, 2013).

Para Allen, O’toole, Mcdonnell e Harris (2003) as estruturas organizacionais de um evento são produtos de estratégias e objetivos e que podem se apresentar de acordo com sua complexidade. As estruturas organizacionais são segmentadas como: estruturas simples, estruturas funcionais, estruturas de matriz baseadas em programas e estruturas multiorganizacionais ou de redes. Sendo a última composta por atividades de maior complexidade, contratando serviços variados de empresas e organizações necessitando de uma série de fornecedores formando uma “organização virtual” ativando redes de trabalho.

Watt (2004) afirma que as estruturas de organização de um evento envolvem pessoas e, por este motivo, carecem de uma relação fundamentada que não somente a administração de recursos materiais. Diante disso, em todo evento, as atividades relacionadas são roteirizadas pelo cerimonial, sendo realizadas e geridas por uma equipe experiente de promotores de eventos trabalhando conjuntamente com a comissão organizadora. Para o autor, as estruturas organizacionais de um evento podem ser entendidas como atividades subordinadas à comissão principal, comissão organizadora.

A Fase Pré-Evento é quando se elabora um plano de execução com estratégias para realização, por isso também é conhecida como Fase Estratégica. A Fase Evento é quando se começa a executar o evento conhecida como Fase de Operacionalização e, por fim, a Fase Pós-Evento é quando se analisa os prós e contras da execução, conhecida como Fase Analítica. Todo o processo de execução na junção das 3 fases é conhecido como Evento. $\mathrm{O}$ planejamento de um evento não é uma fórmula pronta, cada evento apresenta suas particularidades, porém, serviços característicos da Fase Evento e seus pontos de atenção para uma execução eficiente, é que se referem às atividades operacionais.

A Operacionalização compreende a segunda fase de realização do planejamento de um evento, quando a elaboração de todo projeto (planejamento) foi desenvolvido e, passa-se 
para organização, ou seja, a contratação dos serviços e coordenação de atividades inerentes ao evento por meio de cronograma de execução direcionado pelo planejamento do evento. A comissão organizadora do evento irá atribuir, neste momento, às responsabilidades de toda equipe organizadora distribuindo funções a serem desenvolvidas por cada membro da equipe para que as atividades da Fase Evento sejam cumpridas (Cesca, 1997).

Desta forma, diversas são as atividades que podem estar envolvidas na Fase Evento Operacionalização e, estas vão depender da finalidade deste evento, da área de interesse e suas características e, principalmente, dos objetivos que se pretende atingir que serão claramente expostos na complexidade de elaboração do planejamento deste evento feito pela empresa organizadora em conjunto com a empresa promotora.

Zanella (2006) destaca como importantes para o planejamento as atividades de: coordenação e controle, secretaria executiva, recepção e atendimento, marketing e vendas, publicidade e comunicação e serviços de manutenção das instalações e equipamentos. Estas não são atividades exclusivamente relacionadas à Operacionalização.

As atividades diretamente realizadas na Fase Evento - Operacionalização são: coordenação, secretaria executiva, finanças, divulgação e comunicação, transporte, recepção e recursos humanos, a estas se atribuem funções que facilitam o satisfatório andamento do evento. A coordenação gere as atribuições e funções de toda equipe organizadora segmentando-a por comissões. A secretaria executiva gere as inscrições e, credenciamento e recepção dos participantes do evento. As finanças gere o controle de contratos e execução dos serviços. A divulgação e comunicação faz a gerência da marca do evento e a mídia envolvida na comunicação. Os transportes fazem a administração dos recursos de transporte necessário para equipe organizadora, participantes e acompanhantes do evento. $O$ receptivo (recepcionistas ou promotores de eventos) executa os aspectos materiais e imateriais do evento no que se refere às atividades listadas no roteiro cerimonial. E os recursos humanos contratam os profissionais necessários para operação de recursos.

As empresas no segmento de eventos podem se distinguir como: promotoras e organizadoras, pois, apresentam natureza jurídica distinta: associações e empresas. As empresas promotoras de eventos normalmente (a maioria) são associações que promovem eventos segmentados por sua área de interesse e podem ser: científicos, técnicos e profissionais. As empresas promotoras, não tem expertise no planejamento e organização de eventos e, para isto, contratam as empresas organizadoras executarem o evento que irão promover (Matias, 2013). 
Todas estas atividades setorizadas e, muitas outras, do planejamento de um evento são competências atribuídas às empresas organizadoras de eventos e demandam cuidados aos detalhes e conhecimento elaborado (expertise e know-how) para serem desenvolvidas.

\subsection{Empresas organizadoras de eventos: das competências a contratação de}

\section{recursos humanos}

As empresas organizadoras de eventos são de origem empresarial ou corporativa e abarcam quase todos os tipos de eventos existentes. São as empresas organizadoras que contratam profissionais e serviços para assegurar o desenvolvimento do planejamento do evento. Por meio de planejamento, as empresas organizadoras poderão gerir as atividades inerentes ao evento de forma a atender as demandas e a expectativa da empresa promotora que a contratou. As empresas organizadoras planejam e gerem os eventos trabalhando com parceiros, fornecedores, terceirizados e até voluntários (pessoa jurídica ou pessoa física) e estes compreendem profissionais de diversas atividades, assim, a equipe de uma empresa gestora é especializada.

A empresa organizadora, segundo Andrade (2007) passa a responsabilizar-se especialmente pelo planejamento, pela administração financeira e pelos recursos humanos (RH) do evento para que os serviços sejam prestados atendendo as exigências de contrato e as especificações técnicas para atingir a melhor qualidade na prestação dos serviços e, para garantir o sucesso do evento, utiliza-se o direito do consumidor como código de ética para estas contratações. Sobre ela, recaem todas as responsabilidades de elaboração, estratégia, operação e análise de um evento por meio do planejamento em conjunto com a empresa promotora que dará as diretrizes do evento.

Segundo Allen et al. (2003) as empresas organizadoras de eventos devem se atentar com leis e estatutos relativas à relação patrão-empregado devido a terceirização de RH's. O autor ainda orienta que para estruturar as equipes, a atuação e as funções de cada uma delas, é preciso estabelecer as bases de gerenciamento e seus representantes que são formadas pelos colaboradores contratados da empresa organizadora para que cada responsável possa gerir suas atividades no evento e seus contratos, como por exemplos: os promotores de eventos, seguranças, equipe de manutenção e operadores de áudio e vídeo.

No relatório II Dimensionamento Econômico da Indústria de Eventos do Brasil realizado com 2.700 empresas organizadoras de eventos nacionais pelo Serviço Brasileiro de Apoio a Micro e Pequena Empresa (SEBRAE) em conjunto com a Associação Brasileira de 
Empresas de Eventos (ABEOC), levantou-se dados da empregabilidade da área de eventos indicando que há 132.034 empregos diretos e 1.761.374 empregos terceirizados. Sendo três empregos indiretos para cada direto, ou seja, são 5.680.257 empregos indiretos sob medição do efeito multiplicador na indústria turística nacional (Maioli, Stadler, \& Ardigo, 2018).

Isto caracteriza uma movimentação de contratação ativa no setor, e que é oriunda da terceirização, visto que, os vínculos e tributações empregatícias nacionais oneram as empresas organizadoras de eventos para investirem na contratação formal por meio de CLT considerando a relação devido ao tempo de contrato formal e ao contrato temporário.

O receptivo de um evento são os recursos humanos terceirizados contratados para desenvolver as atividades inerentes segmento. Eles representam o primeiro contato direto do participante com o evento e cumprem as atribuições da comissão organizadora desempenhando atividades e funções listadas no planejamento do evento como um todo (Fortes \& Silva, 2011).

Estes profissionais são conhecidos como promotores de eventos (receptivo ou recepcionistas) que, tecnicamente, conhecem as rotinas dos eventos, suas peculiaridades e complexidades; administrando os acontecimentos conforme o planejamento elaborado. São profissionais independentes e que poderão oferecer seus serviços às empresas organizadoras de eventos informalmente, apenas recebem este nome, pois, divulgam o evento e corroboram com a estrutura da organização.

Os promotores de eventos irão desenvolver atividades de recepção, orientação, coordenação, acompanhamento de check list, atendimento de credenciamento e, atendimentos em geral desempenhando funções como as de: recepcionista, coordenadores, produtores, entre outras. Por ser uma função com muitas atribuições permite atuações variadas de profissionais de formações no ensino superior e de conhecimento técnico diverso em atividades profissionais anteriores colocando em prática suas habilidades técnicas e científicas para melhor andamento das atividades que desempenham em eventos.

Por não ser uma categoria sindicalizada não se têm estatísticas profissionais quanto seu perfil sociodemográfico, sua área de atuação, rendimento médio, horas trabalhadas, formação e conhecimentos técnicos, com este argumento a pesquisa se justifica. 


\section{MÉTODOS E MATERIAIS}

A metodologia desta investigação está alicerçada em três pilares: pesquisa bibliográfica, documental e empírica de forma qualitativa e quantitativa. A primeira e a segunda, foram realizadas para darem sustentação aos argumentos que viabilizam a pesquisa empírica (qualitativa e quantitativa), formando corpus teórico de entendimento para o leitor acerca da realidade do setor. Segundo Gil (2007, p. 44) “a pesquisa bibliográfica é desenvolvida a partir de material já elaborado, constituído principalmente de livros e artigos científicos". Por este motivo privilegiou-se citar clássicos da literatura especializada no estudo de eventos para disseminar os conhecimentos científicos estruturados da área e, suas definições fundamentadas, nos termos: eventos, planejamento de eventos, fases do planejamento de eventos, captação de eventos e operacionalização de eventos, sem aspas e sem booleanos.

A busca pelos termos foi feita no Acervo Sophia ${ }^{1}$ (online) da biblioteca da Universidade Federal do Paraná - Campus Rebouças. A busca pelos termos foi feita de forma aleatória, manual e não estruturada. Já a busca por artigos científicos se deu pela palavrachave: eventos (sem aspas) na plataforma: Publicações de Turismo da USP², obtendo 270 resultados, sendo analisados apenas os 198 primeiros, fazendo um recorte dos anos de 2012 a 2017. As escolhas de citações se deram inicialmente por um filtro dos títulos, sendo selecionadas 6 publicações de interesse no tema e, posteriormente, restando 5 após a leitura dos artigos na integra. As demais referências se deram por busca no banco de dissertações do Programa de Pós-Graduação em Turismo da $\mathrm{UFPR}^{3}$ e, por busca online realizada diretamente no site da $\mathrm{ICCA}^{4}$ e da $\mathrm{CNI}^{5}$ para confirmação de dados atualizados no setor por meio de análise de relatório anual e manual de eventos empresarial.

Os procedimentos de pesquisa qualitativa e quantitativa utilizados para realização do estudo e elaboração do formulário seguiram as diretrizes de Creswell (2010; 2014). Segundo o autor, as pesquisas qualitativas estruturam-se por meio de intepretações teóricas que informam o estudo do problema de pesquisa atribuindo significados abordados pelos indivíduos ou grupo de indivíduos a um problema social ou humano. Assim, o pesquisador utiliza-se de instrumentos de coleta de dados para investigação indutiva ou dedutiva estabelecendo padrões ou temas por meio de relatório que incluem os relatos dos participantes

\footnotetext{
${ }^{1}$ Recuperado de http://acervo.ufpr.br/index.html.

${ }^{2}$ Recuperado de http://www.each.usp.br/turismo/publicacoesdeturismo/sobre.php.

${ }^{3}$ Recuperado de http://www.prppg.ufpr.br/site/ppgturismo/trabalhos-de-conclusao/.

${ }^{4}$ Recuperado de https://www.iccaworld.org/.

${ }^{5}$ Recuperado de http://www.portaldaindustria.com.br/cni/.
} 
e as reflexões dos pesquisados fazendo uma descrição e análise complexa. Já as pesquisas quantitativas são levantamentos ou experimentos que apresentam descrição numérica de tendências, atitudes ou opiniões de uma população podendo inferir afirmações do comportamento de tal população a partir de resultados obtidos da amostra podendo até controlar o impacto de tratamento administrando fatores que possam influenciar no resultado.

Considerando as definições e indicação do uso dos métodos, um formulário online foi elaborado fazendo uma junção dos procedimentos de pesquisa qualitativa e quantitativa. Com o auxílio da ferramenta Google Forms ${ }^{6}$ estruturou-se um questionário com o objetivo de levantar informações acerca dos promotores de eventos que realizam suas atividades profissionais em Curitiba e Região Metropolitana. O universo escolhido é o locus de análise da pesquisa das autoras e, também, onde ambas exercem suas funções profissionais como docentes.

O formulário foi constituído de 15 questões dividido em 3 seções: sociodemográfico, habilidades e contratação e para responder as questões o tempo médio foi 2 minutos de preenchimento por parte dos respondentes. O link do formulário foi disseminado nas redes sociais (facebook, whastapp e email) da autora 1, onde concentram-se os contatos profissionais de aproximadamente 120 pessoas atuantes na área de eventos priorizando a facilidade de retorno devido a proximidade profissional.

A pesquisa foi aplicada no período entre 20 de dezembro de 2018 e 10 de janeiro de 2019. Obtendo 31 respondentes para análises dos resultados. As perguntas foram divididas em 3 seções: perfil sociodemográfico (gênero, idade, estado civil, onde reside, escolaridade, idioma, profissão, tempo de atuação, tipo de contratação e renda), habilidades (profissão anterior e o motivo de trabalhar com eventos) e contratação (como é contratado nos últimos 4 anos e para que localidade) para que fosse possível compreender se as hipóteses levantadas na introdução confirmam-se ou refutam os resultados que serão apresentados na seção a seguir.

Por ser um formulário digital veiculado pela internet, o preenchimento pelos respondentes se deu de forma espontânea e, desta maneira, o termo de consentimento livre e esclarecido (TCLE) estava implícito.

Os resultados apresentados na próxima seção estão em frequências absolutas, números inteiros seguidos pelas frequências relativas, valores percentuais, com a representação de uma casa decimal após a vírgula. Destaca-se que a confiabilidade estatística dos dados apresentados nesta pesquisa estão em $99,9 \%$, tendo 0,1 ponto percentual de

${ }^{6}$ Recurso de enquete online. 
margem de erro, para mais ou para menos, pois, os cálculos são realizados pela própria ferramenta utilizada para realização dos formulários.

\section{ANÁLISE E INTERPRETAÇÃO DOS RESULTADOS}

$\mathrm{Na}$ seção que estabelece o perfil sociodemográfico observou-se que $25(80,6 \%)$ dos 31 respondentes são do gênero feminino e $6(19,4 \%)$ do gênero masculino. Abriu-se a possibilidade de não indicação de gênero, mas, está opção não foi selecionada. $O$ que confirma que os promotores de eventos são majoritariamente do gênero feminino, mantendose um perfil profissional de recepcionistas mulheres.

Quanto a idade, $14(45,2 \%)$ respondentes tem de 26 a 30 anos, $6(19,4 \%)$ de 31 a 36, $4(12,9 \%)$ de 37 a 40, sendo igualmente representado pela categoria de 18 a 25 anos. Sendo que apenas $3(9,7 \%)$ tem mais de 40 anos. O que configura uma categoria profissional bastante jovem, porém, adulta.

Quanto ao estado civil, $22(71 \%)$ são solteiros, 8 (25,8\%) são casados e $1(3,2 \%)$ divorciado. Percebe-se que devido às atividades de eventos serem intensas, compreendendo finais de semanas, feriados e período de férias, em turnos diversos, o perfil de profissional solteiro se adequa melhor as atividades da área.

Já a origem, são $27(87,1 \%)$ de Curitiba e $4(12,9 \%)$ da Região Metropolitana de Curitiba. Embora os dois principais centros de eventos da cidade localizem-se em regiões opostas, um na Região Metropolitana e outro em Curitiba, a maioria dos profissionais contratados é de Curitiba.

Em relação à escolaridade $13(41,9 \%)$ tem ensino superior, $8(25,8 \%)$ são pósgraduados, $6(19,4 \%)$ tem ensino fundamental e $4(12,9 \%)$ tem ensino técnico. O que representa uma área com profissionais capacitados técnicos e com formação superior. Dos 21 $(67,7 \%)$ que responderam terem curso superior e pós-graduação, suas formações de graduação foram: 5 (20,8\%) em marketing e/ou publicidade, 4 (16,7\%) em administração, 3 (12,5\%) em turismo. O que confirma a área de eventos ter profissionais de marketing e/ou publicidade para desenvolvimentos de atividades de gestão e operacionais devido suas capacidades técnicas e científicas de formação, não desconsiderando áreas complementares como administração e turismo. Outros cursos mencionados: comunicação, eventos, educação física, serviços jurídicos e notariais, enfermagem, design, farmácia, engenharia florestal e relações internacionais. Observa-se que profissionais de outras áreas atuam com eventos. 
Quanto ao idioma, $16(51,6 \%)$ dos 31 respondentes afirmaram ter fluência. Destes 9 $(56,3 \%)$ no idioma inglês, 8 (50\%) no espanhol, 2 (12,5\%) no francês, do restante, 1 (6,3\%) tem fluência em italiano e, na mesma proporção, em alemão sendo que $3(18,9 \%)$ não têm fluência em nenhum idioma. O que confirma que alguns destes têm fluência em dois idiomas, sendo bilíngues e/ou trilíngues e, indicando a importância de ter fluência em inglês e espanhol para execução das atividades como promotores de eventos.

Quanto às funções exercidas em contrato, apenas 29 (93,5\%) dos 31 respondentes responderam a questão, conforme apresentado no gráfico 1 a seguir:

Gráfico 1 - Funções exercidas pelos promotores de eventos

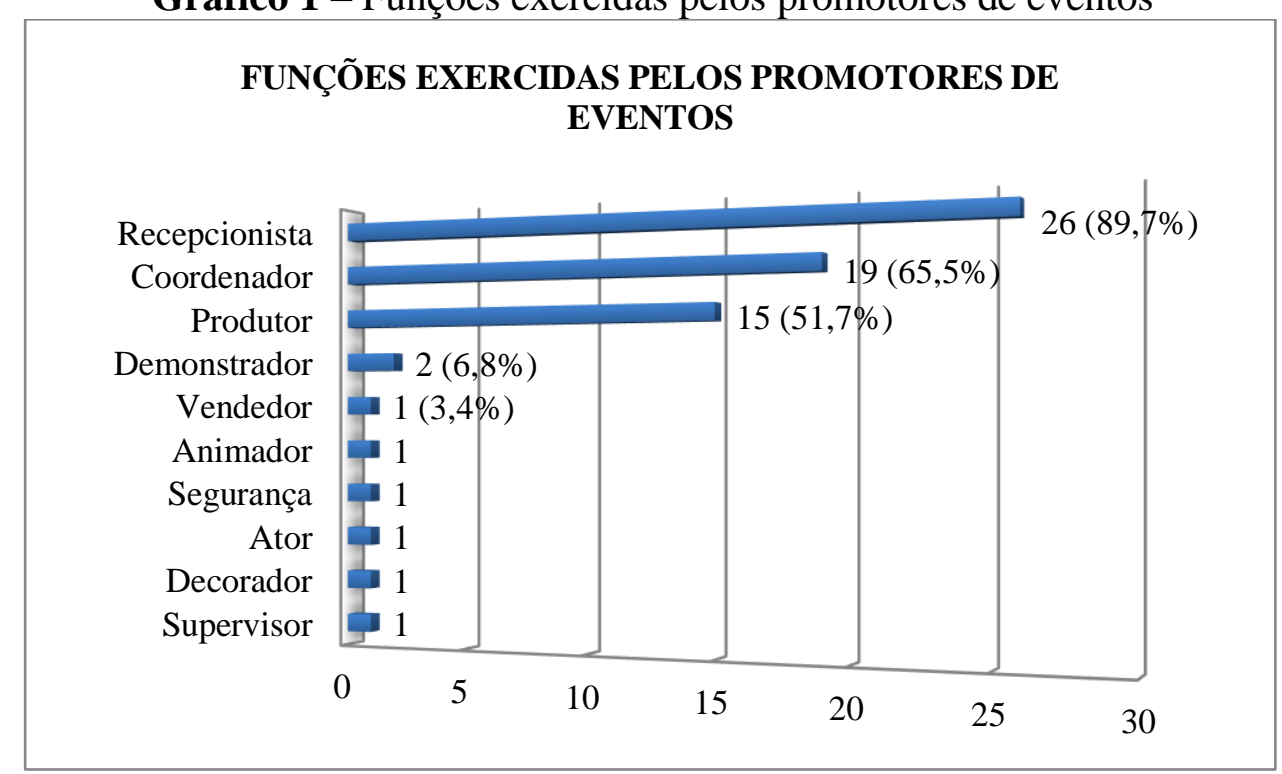

Fonte: Elaborado pelas autoras com base Google Forms, 2019.

Pode-se inferir que os promotores de eventos são contratados para funções diversas em eventos, sendo as principais, recepcionistas de eventos 26 (89,7\%), coordenador de eventos $19(65,5 \%)$ e produtor $15(51,7 \%)$, confirmando que a área demanda profissionais para gestão e operacionalização de atividades da Fase Evento - Operacionalização, conforme referencial teórico, porém, não são todas as funções que apresentam atividades listadas no planejamento conforme Fortes \& Silva (2011). Os resultados indicam outras funções tais: demonstrador, vendedor, animador, segurança, ator, decorador e supervisor.

Quando foram questionados sobre o tempo de atuação dos 31 respondentes; 14 $(45,2 \%)$ tem de 5 a 10 anos de atuação na área, 11 (35,5\%) tem de 1 a 5 anos, 3 (9,7\%) tem de 10 a 15 anos e, $3(9,7 \%)$ mais de 15 anos. O que confirma uma expertise e know-how para execuções de atividades em eventos devido ao tempo de execução das funções.

Quando questionou-se sobre situação profissional verificou-se que $17(54,8 \%)$ são profissionais terceirizados (contratado por empresas organizadoras e de RH para eventos), 13 
$(41,9 \%)$ são profissionais formalizado (MEI ou microempresa) e apenas 1 (3,2\%) profissional contratado por CLT. O que confirma a área ser permeada de terceirização para contratação de RH's conforme publicação de Maioli, Stadler, e Ardigo (2018) sob os dados do relatório II Dimensionamento Econômico da Indústria de Eventos do Brasil (SEBRAE e ABEOC), mas, que já desponta para um perfil mais empreendedor dos profissionais que se formalizam como MEI's ou microempreendedores para atenderem as exigências de contratação das empresas organizadoras fornecimento de nota fiscal para arrecadação de contribuições tributárias formais.

Finalizando esta seção, ao questioná-los sobre a média de rendimento mensal verificou-se dos 31 respondentes:

Gráfico 2 - Rendimento mensal dos promotores de eventos

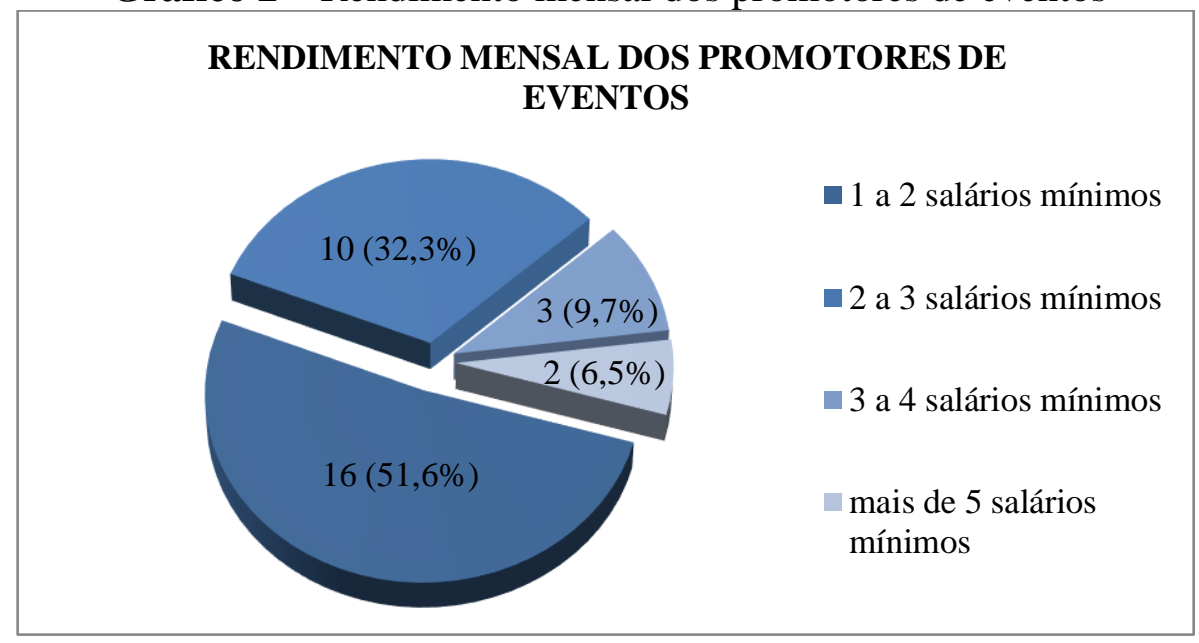

Fonte: Elaborado pelas autoras com base Google Forms, 2019.

Sob esta análise configura-se que os $26(83,9 \%)$ promotores das áreas de eventos recebem rendimentos entre 1 a 3 salários mínimos sendo que uma parcela de 5 (16,2\%) recebem mais de 3 salários mínimos. Percebe-se que os rendimentos médios estão entre R\$ 1.431,00 reais para os que ganham de 1 a 3 salários mínimos e $\mathrm{R} \$ 2.385,00$ para os que ganham de 3 a 5 salários mínimos. Para esta análise considerou o salário mínimo como sendo $\mathrm{R} \$ 954,00$, valor praticado na data de início da realização da pesquisa.

$\mathrm{Na}$ seção que estabelece as habilidades questionou-se sobre as profissões anteriores dos promotores de eventos, e obteve-se 25 (85,6\%) respondentes. As respostas foram diversas: guia bilíngue, recepcionista em multinacional, administrativo, secretaria, digitadora, telemarketing, sempre trabalhei com eventos, modelo, cantora e professora de inglês, vendedor, degustadora, hotelaria, televendas, estagiário, farmacêutica, atendente de doceria, balconista e funcionária pública. Nota-se então que profissionais de outras áreas se 
interessarem em trabalhar com eventos devido aos rendimentos por dia e ao trabalho poder ser desempenhado fora do horário do trabalho formal. Mas o que também, configura profissionais da área com característica de trabalhos anteriores que contribuem com as funções em eventos como: guias bilíngues, secretarias e profissionais de eventos e hotelaria.

Ao serem questionados sobre os motivos de se trabalharem com eventos, foi dada quatro opções inicias: 1 - Porque me permite trabalhar por dia, 2 - Porque me permite ter dias para organizar minha vida pessoal, 3 - Porque me permite uma remuneração satisfatória e 4 Porque a área me permite utilizar meus conhecimentos bilíngues e/ou trilíngues e não encontrei função que me remunerasse melhor. Os 31 respondentes disseram: 13 (41,9\%) porque me permite ter dias para organizar minha vida pessoal, $6(19,4 \%)$ porque me permite trabalhar por dia, $3(9,7 \%)$ porque me permite uma remuneração satisfatória e $2(6,5 \%)$ porque a área me permite utilizar meus conhecimentos bilíngues e/ou trilíngues e não encontrei função que me remunerasse melhor. Outras opções foram adicionadas pelos respondentes como: por que se adquirir experiências em diversos setores e conhece muitas pessoas, por gosta da área e conhecer lugares diferentes, por ser dinâmica e eu poder fazer meu "salário", porque estudo e trabalho, porque gosto de ganhos extras, por que amo o que faço e porque não consegui retornar a área que trabalhava tendo mais oportunidades na área de eventos. As respostas confirmam que o setor de eventos acolhe profissionais de diferentes áreas por sua diversidade de atividades e pelo dinamismo de funções sendo mercado de ganhos extras para outros profissionais que querem aumentar seus rendimentos mensais.

Por fim, a seção contratação questionou-os sobre os últimos quatro anos como tem sido as contratações das empresas. Foram dadas quatro opções iniciais: casting de agências, entrevista em RH's de agência, sites de empresas organizadoras e redes sociais e aplicativos de contato. Dos 31 respondentes, 10 (32,3\%) são contratados nos últimos quatro anos por redes sociais e aplicativos de contato, outros 10 (32,3\%) por indicação de amigos (item que foi adicionado pelos respondentes), $8(25,3 \%)$ casting de agências, $1(3,2 \%)$, por agências que conhecem o meu trabalho e entram em contato, 1 (3,2\%) tenho empresa e, 1 (3,2\%) sou produtor fixo de algumas agências e atendo clientes próprios por indicação. Nenhum deles responderam as opções: entrevista em RH's de agência e sites de empresas organizadoras. $\mathrm{O}$ que demonstra uma mudança de perfil de contratação migrando para o meio virtual e redes de contatos fazendo a área perder o perfil de contratação pessoal e formal.

E finalmente, os 31 respondentes foram questionados sobre para qual local são contratados para exercer as suas funções: 30 (96,8\%) responderam Curitiba e, apenas 1 $(3,2 \%)$ Região Metropolitana, isso confirma que os profissionais são mais contratados para 
exercerem suas funções no centro de eventos de Curitiba devido a maior rotatividade de eventos deste estabelecimento.

Esta pesquisa, portanto, teve o objetivo de analisar o perfil profissional dos promotores de eventos da cidade de Curitiba e Região Metropolitana para conhecê-los sociodemográfico e profissionalmente interpretando cenário contemporâneo por meio de características destacadas. Assim, estruturou-se uma pesquisa quali-quanti para analisar e interpretar formando perfil a partir de resultados obtidos em um formulário online.

\section{CONSIDERAÇÕES FINAIS}

Reconhecer que os eventos são classificados em tipos de acordo com seus interesses e características e que, o planejamento de um evento é composto de fases que representam as suas principais atividades de execução, permite compreender, inicialmente, as bases de desenvolvimento e estudo desta área complexa. Perceber que estas fases (de estruturação, operação e análises) compõem um método organizativo e simplificado direcionam ações para um desempenho de excelência.

As atribuições das empresas organizadoras de eventos têm, entre inúmeras atividades, a responsabilidade de: administrar ativos materiais e imateriais, além de, contratar e gerir RH's seccionando-os em equipes coordenando suas funções. Todo este processo que demanda operação é desempenhado por pessoas, profissionais que, por formação e/ou capacidade técnica, desenvolvem atividades predeterminadas em roteiro.

Conhecer estes profissionais, mesmo que o período de contratação seja reduzido a um dia facilita o entendimento de um perfil pouco conhecido da literatura acadêmica: os promotores de eventos. Profissionais comumente chamados de recepcionistas de eventos ou receptivo de eventos que angariam conhecimento de outras funções para desempenharem suas atividades em eventos e, Curitiba por se destacar com uma boa colocação internacional e nacional como universo de destinos de eventos deve-se preocupar com seu capital humano atuante na área para que seja possível manter-se como oferta atrativa em potencial.

Nos resultados apresentou-se um perfil sociodemográfico e profissional de promotores de eventos de Curitiba e Região Metropolitana formado, majoritariamente, por mulheres, entre 26 e 30 anos, solteiras, residentes de Curitiba, formadas em curso superior de marketing e/ou publicidade que são fluentes em inglês, espanhol e/ou são bilíngues nos dois idiomas, contratadas como recepcionistas, coordenadoras e produtoras, entre outros, que tem entre 5 e 10 anos de atividade profissional na área de eventos, que são terceirizadas 
contratadas por empresas organizadoras de eventos, tendo rendimentos mensais médios de R\$ 1.431,00 (1 a 3 salários mínimos). Estas atuavam em atividades diversas, antes de trabalhar com eventos, em algumas áreas como guia de turismo bilíngue, hotelaria, secretária e etc. e que optaram trabalhar com eventos porque lhes permite dias livres para organizar a vida pessoal, sendo contratadas nos últimos 4 anos, primordialmente, por redes sociais e aplicativos de contato e indicação de amigos, geralmente, sendo contratadas para trabalhar na cidade de Curitiba.

O perfil apresentado responde os objetivos textuais, ou seja, ao relacionar os resultados obtidos na pesquisa com o suporte teórico utilizado apresenta-se como primeira hipótese refutada de que estas profissionais tinham formações similares às áreas de turismo, hotelaria e eventos, mas, sendo confirmada, não em sua maioria. Estas são oriundas de cursos de marketing e/ou publicidade e, que suas experiências profissionais são advindas de outras áreas. A segunda hipótese levantada foi que devido às transformações econômicas e sociais que, afetaram as relações de consumo por meio de plataformas digitais, reduziram os intermediários no processo e as contratações profissionais no segmento de eventos passaram a ser online por meio de sites de cadastros das empresas organizadores confirmando-se com sendo as profissionais contratadas nos últimos 4 anos por meio de redes sociais e aplicativos de contato e indicação de amigos e, confirmou-se também, a emersão de profissionais de outras áreas em incursão neste mercado devido possibilidade de organização pessoal dada a flexibilidade de contratação, carga horária profissional e suas remunerações por contrato temporário acima da média que configura uma renda extra.

O alcance do estudo teve locus regional por acesso facilitado ao universo da autora 1. A expectativa era de um universo composto por aproximadamente 120 pessoas, destas 31 $(25,8 \%)$ responderam, ou seja, o que representa $1 / 4$ de contribuições com informações. Embora o número de retorno dos formulários não tenha atingido $30 \%$, do universo investigado, não se desqualifica os resultados, visto que as respostas se repetiam confirmando uma amostra por conveniência e, que o universo de acesso profissional da autora 1 não representa todo o universo de promotores de eventos existentes em Curitiba e RM.

Recomenda-se que para estudos futuros seja aplicada à mesma metodologia e métodos colocado nas perguntas abertas à opção de resposta obrigatória. Propõe-se que sejam aplicados formulários em outros municípios para composição de dados estatísticos do universo nacional visto a terceirização dificulta a mensuração da categoria, bem como a falta de sindicalização. 


\section{AGRADECIMENTOS}

Aos 31 respondentes deste Universo que, anonimamente, viabilizaram a realização da pesquisa.

\section{REFERÊNCIAS}

Allen, J., O’toole, W., Mcdonnell, J., \& Harris, R. (2003). Organização e gestão de eventos. Rio de Janeiro: Elsevier.

Andrade, R. B. (2007). Manual de eventos. (3a. ed.). Caxias do Sul, RS: Educs.

Aquino, M., \& Brambatti, L. E. (2018). O comportamento do consumidor de serviços turísticos na sharing economy: diagnóstico teórico-analítico para uma compreensão do tema. XV Seminário Anual da Associação Nacional de Pesquisa e Pós-Graduação em Turismo, Curitiba, PR, Brasil. Recuperado em 19, janeiro, 2019, de https://www.anptur.org.br/anais/anais/files/15/1018.pdf.

Aquino, M., \& Silveira, C. E. (2018). A informalidade no mercado de trabalho dos serviços turísticos: proposta metodológica de investigação sob pesquisa bibliográfica na ótica da sharing economy. XV Seminário Anual da Associação Nacional de Pesquisa e PósGraduação em Turismo, Curitiba, PR, Brasil. Recuperado em 19, janeiro, 2019, de https://www.anptur.org.br/anais/anais/files/15/1020.pdf.

Arruda, M., \& Tarsitano, P. (2012). Eventos: momentos pensados, desenhados e projetados para a comunicação e o relacionamento humano. Revista Hospitalidade, IX(2), p. 199-217.

Bahl, M. (2004). Fatores ponderáveis no turismo: sociais, culturais e políticos. Curitiba: Protexto.

Cesca, C. G. G. (1997). Organização de Eventos: Manual para planejamento e execução. São Paulo: Summus.

Confederação Nacional Da Indústria - CNI. (2005). Manual de Eventos. Brasília: CNI.

Creswell, J. W. (2010). Projeto de pesquisa: métodos qualitativos, quantitativos e mistos. (3a. ed.). Porto Alegre: Artmed.

Creswell, J. W. (2014). Investigação qualitativa e projeto de pesquisa. Porto Alegre: Penso Editora LTDA.

Dotto, D. M. R, Cerezer, L. C, Pons, M. E. D., \& Denardin, A. C. M. (2017). A dinâmica do turismo de eventos no estado do Rio Grande do Sul/Brasil, no contexto do planejamento e da comunicação. Revista Eletrônica Administração e Turismo, 11(6), p. 1349-1363.

Fortes, W. G. E., \& Silva, M. B. R. (2001). EVENTOS: Estratégias de planejamento e execução. São Paulo: Sumus.

Giacaglia, M. C. (2003). Organização de Eventos: Teoria e Prática. São Paulo: Pioneira Thomson Learning.

Gil, A. C. (2007). Métodos e técnicas de pesquisa social. (5a. ed.). São Paulo: Atlas. 
International Congress and Convention Association - ICCA. (2018). Statistics Report Country \& City Ranking. Public Abstract: ICCA.

Klein, S. R. (2017). Eventos de incentivo e ROI - retorno sobre investimento, qual é o saldo? Dissertação de mestrado em Turismo da UFPR, Universidade Federal do Paraná, Curitiba, PR, Brasil.

Maioli, M. R., Stadler, A., \& Ardigo, C. M. (2018). Estratégias competitivas usadas pelas empresas de eventos de Curitiba. Applied Tourism, 3(1), p. 01-17.

Matias, M. (2013). Organização de eventos: procedimentos e técnicas. (6a. ed.) Barueri, SP: Manole.

Nichols, B. C. (1989). Gerenciamento profissional de eventos. Fortaleza: ABC Fortaleza.

Oliveira, B. D, Gândara, J. M. G., \& Oliveira, B. (2017). Escolha de destino para eventos: Uma análise dos atributos considerados na tomada de decisão por organizadores e promotores de eventos. Revista de Turismo Contemporâneo, 5(1), p. 1-22.

Paixão, D. L. D. (2014). A vocação de Curitiba para turismo de negócios e eventos. Turismo \& Sociedade, 7(1), 174-176.

Watt, D. C. (2004). Gestão de eventos em lazer e turismo. Porto Alegre, RS: Bookman.

Zanella, L. C. (2006). Manual de Organização de eventos: planejamento e operacionalização. (3a. ed.). São Paulo: Atlas.

\section{FORMATO PARA CITAÇÃO DESTE ARTIGO}

AQUINO, M. \& TELES, M. A. (2019). Análise do perfil sociodemográfico e profissional do Promotor de eventos de Curitiba e Região Metropolitana (Paraná, Brasil). Revista de Turismo Contemporâneo, 7, Edição Especial, 85-103.

https://doi.org/10.21680/2357-8211.2019v7n0ID16911 